\title{
Effect of Drying Temperature on Iron Fischer-Tropsch Catalysts Prepared by Solvent Deficient Precipitation
}

\author{
Michael K. Albretsen, ${ }^{1}$ Baiyu Huang, ${ }^{2}$ Kamyar Keyvanloo, ${ }^{1}$ Brian F. Woodfield, \\ Calvin H. Bartholomew, ${ }^{1}$ Morris D. Argyle, ${ }^{1}$ and William C. Hecker ${ }^{1}$ \\ ${ }^{1}$ Department of Chemical Engineering, Brigham Young University, Provo, UT 84602, USA \\ ${ }^{2}$ Department of Chemistry and Biochemistry, Brigham Young University, Provo, UT 84602, USA
}

Correspondence should be addressed to Baiyu Huang; baiyu.huang@gmail.com

Received 1 February 2017; Revised 28 March 2017; Accepted 20 April 2017; Published 29 May 2017

Academic Editor: Jean M. Greneche

Copyright ( 2017 Michael K. Albretsen et al. This is an open access article distributed under the Creative Commons Attribution License, which permits unrestricted use, distribution, and reproduction in any medium, provided the original work is properly cited.

\begin{abstract}
A novel solvent deficient precipitation (SDP) method to produce nanoparticles was studied for its potential in Fischer-Tropsch synthesis (FTS) catalysis. Using $\mathrm{Fe}\left(\mathrm{NO}_{3}\right)_{3} \cdot 9 \mathrm{H}_{2} \mathrm{O}$ as the iron-containing precursor, this method produces ferrihydrite particles which are then dried, calcined, reduced, and carbidized to form the active catalytic phase for FTS. Six different drying profiles, including final drying temperatures ranging between 80 and $150^{\circ} \mathrm{C}$, were used to investigate the effect of ammonium nitrate (AN), a major by-product of reaction between $\mathrm{Fe}\left(\mathrm{NO}_{3}\right)_{3} \cdot 9 \mathrm{H}_{2} \mathrm{O}$ and $\mathrm{NH}_{4} \mathrm{HCO}_{3}$ in the SDP method. Since AN has two phase-transitions within this range of drying temperatures, three different AN phases can exist during the drying of the catalyst precursors. These AN phases, along with physical changes occurring during the phase transitions, may affect the pore structure and the agglomeration of ferrihydrite crystallites, suggesting possible reasons for the observed differences in catalytic performance. Catalysts dried at $130^{\circ} \mathrm{C}$ showed the highest FTS rate and the lowest methane selectivity. In general, better catalytic performance is related to the AN phase present during drying as follows: phase III > phase II > phase I. However, within each AN phase, lower drying temperatures led to better catalytic properties.
\end{abstract}

\section{Introduction}

Fischer-Tropsch synthesis (FTS) is a proven process for converting low-value syngas obtained from natural gas, coal, and/or biomass into hydrocarbon fuels [1]. Significant efforts have been exerted on the development of FTS catalysts to improve the efficiency and economics of this process. For hydrogen-deficient syngas obtained from coal or biomass, iron based FTS catalysts are generally preferable to cobalt catalysts, due to their relatively low cost, low methane selectivity, and high water-gas shift (WGS) activity [2-5].

Previous research on iron FTS catalyst preparation has shown that the catalytic performance and physical characteristics are influenced by a number of variables, including the selection of catalytic phase, type of promoter and support, and method of active catalytic phase loading [6]. Among these variables, drying is often viewed as a routine procedure that has minimal, if any, effect on the final precipitated catalysts [7]. Earlier research indicated that drying is routine for solid precipitation but is crucial for hydrogel and flocculates [6]. More recent studies have been conducted on the effects of drying on the distribution of active sites in supported catalysts. Among many, these studies have shown that the desired distribution of active sites can be obtained by changing drying temperature [8], impregnation time [9], and the metal solutions used during synthesis [10]. Drying rate has been shown to affect the particle morphology and particle size, as well [11]. A study by Toupance et al. reported that drying had varying effects on particle size, depending on copper loading, for silica-supported copper catalysts used for many reactions, including hydrogenation [12]. In some cases, the active phase is only formed under certain drying conditions [13]. In other cases, freeze-drying the catalyst produces a more uniform particle size distribution [14].

As mentioned previously, the drying step is often thought to be trivial in the preparation of precipitated catalysts. 
TABLE 1: Ammonium nitrate phase properties as a function of temperature.

\begin{tabular}{lccc}
\hline Phase & Stable temperature range $\left({ }^{\circ} \mathrm{C}\right)$ & Structure & Unit cell volume $\left(\AA^{3}\right)$ \\
\hline I & $32-84$ & Orthorhombic & 83.80 \\
II & $84-125$ & Tetragonal & 80.30 \\
III & $125-169$ & Cubic & 83.45 \\
Liquid & 169 & Liquid & - \\
\hline
\end{tabular}

Recently, a novel, solvent deficient method for creating nanoparticles was discovered by the BYU Department of Chemistry and Biochemistry and Cosmas, Inc. [15-17]. Brunner et al. extended this method to prepare an iron heterogeneous catalyst for Fischer-Tropsch synthesis that is known as the solvent deficient precipitation (SDP) method [18]. Iron catalysts prepared by the SDP method produce a substantial amount of ammonium nitrate $\left(\mathrm{NH}_{4} \mathrm{NO}_{3}\right)$ as a byproduct of the reaction. Ammonium nitrate (AN) has been well studied, specifically for its uses as a rocket propellant [19], but it is an interesting compound relevant to catalyst drying because it undergoes four pertinent phase transitions between $30^{\circ} \mathrm{C}$ and $169^{\circ} \mathrm{C}$, as shown in Table 1 [20]. These different phases have different crystal structures and potentially provide unique morphological influences on the ferrihydrite while it is drying.

In this study, six catalysts were prepared using the SDP method under the same conditions except for their drying temperatures. The objective of this study was to determine how drying temperature affects the properties and activity for iron Fischer-Tropsch catalysts made using the SDP method. The effect of ammonia phase transitions at a series of drying temperatures on catalyst pore structure, crystallinity, reducibility, and catalytic performance was investigated and is discussed.

\section{Experimental}

2.1. Catalyst Preparation. Six catalysts were prepared using the novel solvent deficient precipitation method, in which iron nitrate nonahydrate $\left(\mathrm{Fe}\left(\mathrm{NO}_{3}\right)_{3} \cdot 9 \mathrm{H}_{2} \mathrm{O}\right)$ added to ammonium bicarbonate $\left(\mathrm{NH}_{4} \mathrm{HCO}_{3}\right)$ creates ferrihydrite $\left(\mathrm{Fe}_{10} \mathrm{O}_{14}(\mathrm{OH})_{2}\right)$ particles that later reduce to iron metal during reduction. The nominal composition of each catalyst on a relative mass basis is $100 \mathrm{Fe} / 5 \mathrm{Cu} / 4 \mathrm{~K} / 16 \mathrm{SiO}_{2}$. The silica textural modifier was added to the iron and copper salts (acid), while the potassium promoter (potassium bicarbonate) was added to the ammonium bicarbonate (base) before combining and mixing all components during the SDP of the catalyst precursor. In a typical preparation, $4.822 \mathrm{~g}$ fumed $\mathrm{SiO}_{2}$ (Cab-O-Sil-M4) was added to $217.0 \mathrm{~g}$ $\mathrm{Fe}\left(\mathrm{NO}_{3}\right)_{3} \cdot 9 \mathrm{H}_{2} \mathrm{O}$ (Sigma-Aldrich, ACS, $\geq 98 \%$ ) and $5.485 \mathrm{~g}$ $\mathrm{Cu}\left(\mathrm{NO}_{3}\right)_{2} \cdot 2.5 \mathrm{H}_{2} \mathrm{O}$ (Anachemia, 98-102\%) and mixed well using a pestle in a large mortar. In a separate container, $3.071 \mathrm{~g} \mathrm{KHCO}_{3}$ (Sigma-Aldrich, 100.1\%) was mixed with $129.0 \mathrm{~g} \mathrm{NH}_{4} \mathrm{HCO}_{3}$ (Baker, 21.30-21.73\% as $\mathrm{NH}_{3}$ ), which was added to the metal salt mixture. The combined mixture of dry powders was vigorously mixed with the pestle, during which waters of hydration were released to produce a liquid
TABLE 2: Mass loss during drying of different catalysts.

\begin{tabular}{lcc}
\hline Catalysts & Final dry temp $\left({ }^{\circ} \mathrm{C}\right)$ & Mass loss $(\%)$ \\
\hline C80 & 80 & 39.3 \\
C100 & 100 & 43.7 \\
C115 & 115 & 40.8 \\
C130 & 130 & 43.2 \\
C130b & 130 & 42.1 \\
C150 & 150 & 48.0 \\
C150NP & 150 & 55.5 \\
Theoretical water loss & & 34.4 \\
\hline
\end{tabular}

${ }^{*}$ All catalysts were predried at $60^{\circ} \mathrm{C}$ except $150 \mathrm{NP}$.

slurry. Mixing continued for approximately 20 minutes until precipitation of a paste of $\mathrm{Fe}$ and $\mathrm{Cu}$ hydroxides, referred to as the precursor catalyst, was complete as indicated by cessation of $\mathrm{CO}_{2}$ release as bubbles [18].

All but one of the precursors were dried initially in a preheated oven at $60^{\circ} \mathrm{C}$ for $16 \mathrm{~h}$, followed by a $6 \mathrm{~h}$ final dry at $80^{\circ} \mathrm{C}, 100^{\circ} \mathrm{C}, 115^{\circ} \mathrm{C}, 130^{\circ} \mathrm{C}$, or $150^{\circ} \mathrm{C}$ (see Table 2 ) with a ramp rate of $3^{\circ} \mathrm{C} / \mathrm{min}$ in $100-200 \mathrm{~cm}^{3} / \mathrm{min}$ of flowing air. One catalyst was dried for $8 \mathrm{~h}$ at $150^{\circ} \mathrm{C}$ directly and was named with the final drying temperature and the suffix NP for no predry. Catalysts were named based on the final drying temperature. Several experiments, including fixed-bed rate analysis, nitrogen physisorption, and XRD, were repeated using catalyst 130 from the same batch after calcination, which are designated 130r to show the reproducibility of the data within a catalyst batch. Catalyst 130 was completely remade, designated as $130 \mathrm{~b}$, and subjected to the same experiments. Both sets of data for both preparations (130 and 130b) are shown in the results.

After drying, the catalysts were calcined in flowing dry air at $300^{\circ} \mathrm{C}$ to decompose the ammonium nitrate according to their temperature programmed oxidation (TPO) profile. The temperature profile for the calcinations was a ramp of $1^{\circ} \mathrm{C} / \mathrm{min}$ to $90^{\circ} \mathrm{C}$ followed by a $1 \mathrm{~h}$ hold. A second ramp of $1^{\circ} \mathrm{C} / \mathrm{min}$ to $210^{\circ} \mathrm{C}$ was followed by a $4 \mathrm{~h}$ hold. Finally, a $0.5^{\circ} \mathrm{C} / \mathrm{min}$ ramp was applied up to $300^{\circ} \mathrm{C}$, with a temperature hold for $6 \mathrm{~h}$.

Prior to catalytic use, the catalysts were reduced by ramping the temperature by $1^{\circ} \mathrm{C} / \mathrm{min}$ from room temperature to $300^{\circ} \mathrm{C}$ in a mixture of $90 \% \mathrm{He}$ and $10 \% \mathrm{H}_{2}$ and held for $16 \mathrm{~h}$, with the last $6 \mathrm{~h}$ in $100 \% \mathrm{H}_{2}$, according to their temperature programmed reduction profile (TPR). $300^{\circ} \mathrm{C}$ was chosen to avoid overreduction to metallic iron that would lead to lower surface areas of the active phase. All reactant gases were 
Airgas UHP. After reduction, the catalysts were cooled to $25^{\circ} \mathrm{C}$ and passivated by slowly introducing a small amount of air for $30 \mathrm{~min}$ to form an oxide layer on the catalyst surface.

2.2. Characterization. Specific surface areas and pore volumes were obtained by nitrogen physisorption analysis, using a Micromeritics TriStar 3000 apparatus. For each catalyst, $0.2-0.5 \mathrm{~g}$ of sample was degassed under vacuum at $120^{\circ} \mathrm{C}$ overnight. Their surface areas (SAs) were calculated using BET theory using $P / P_{0}$ ranging from 0.02 to 0.20 , pore volumes (PVs) were determined at a single point $P / P_{0}$ at 0.995 , and pore size distributions (PSD) were calculated using a slit pore geometry (SPG) model [21].

Temperature programmed characterizations, including temperature programmed reduction (TPR), temperature programmed oxidation (TPO) in air, extent of reduction (EOR), and CO uptake, were performed using a Mettler Toledo TGA/DSC 1 with a sample size of $15-25 \mathrm{mg}$. TPR experiments were used to determine catalyst reducibility by measuring the rate of mass loss during a temperature ramp of $3^{\circ} \mathrm{C} / \mathrm{min}$ from ambient to $700^{\circ} \mathrm{C}$ in $100 \mathrm{~cm}^{3} / \mathrm{min} 10 \%$ $\mathrm{H}_{2} / \mathrm{He}$. TPO experiments were used to design temperature programmes for bulk calcination. The rate of mass loss during a constant temperature ramp of $3^{\circ} \mathrm{C} / \mathrm{min}$ from ambient temperature to $700^{\circ} \mathrm{C}$ in $100 \mathrm{~cm}^{3} / \mathrm{min}$ of $50 \%$ air/He was analyzed to determine appropriate temperature ramps and soaks for controlling byproduct decomposition at low rates. Isothermal oxygen titration experiments were used to determine the extent of reduction (EOR) to Fe metal following reduction. EOR was calculated from $\mathrm{O}_{2}$ uptake during oxidation at $400^{\circ} \mathrm{C}$ after rereduction of previously passivated catalysts for $6 \mathrm{~h}$ at $300^{\circ} \mathrm{C}$ in $10 \% \mathrm{H}_{2} / \mathrm{He}$. CO uptake was measured at $25^{\circ} \mathrm{C}$ in $10 \% \mathrm{CO} / \mathrm{He}$, following rereduction of passivated catalysts at $300^{\circ} \mathrm{C}$ for $6 \mathrm{~h}$ in $10 \% \mathrm{H}_{2} / \mathrm{He}$ and a $1 \mathrm{~h}$ purge in $100 \% \mathrm{He}$ at $290^{\circ} \mathrm{C}$.

X-ray Diffraction (XRD) was obtained via a PANalytical X'Pert Pro diffractometer with a $\mathrm{Cu}$ source and a $\mathrm{Ge}$ monochromator which was tuned to the $\mathrm{Cu}-\mathrm{K}_{\alpha 1}$ wavelength $(\lambda=1.54 \AA)$. A scan step time of $350 \mathrm{~s}$ with a rate of $0.016^{\circ}$ between 10 and $90^{\circ}$ was used.

Fischer-Tropsch synthesis rate data were obtained in a fixed-bed reactor described previously (K. M. Brunner Doctor of Philosophy, Brigham Young University, 2012). Each sample to be tested $(0.25 \mathrm{~g}, 250-590 \mu \mathrm{m})$ was diluted with quartz sand $(-50 /+70$ mesh) to improve temperature stability in the catalytic zone. Before FTS, the sample was reduced in situ at $280-320^{\circ} \mathrm{C}$ in $10 \% \mathrm{H}_{2} / \mathrm{He}$ for $10 \mathrm{~h}$ followed by $100 \% \mathrm{H}_{2}$ for $6 \mathrm{~h}$. Then, the catalyst was cooled to $180^{\circ} \mathrm{C}$ and the system was pressurized to $2.1 \mathrm{MPa}$ in flowing syngas $\left(\mathrm{H}_{2}: \mathrm{CO}=1\right)$. The catalyst was then heated (still in syngas) and activated at $280^{\circ} \mathrm{C}$ and a CO conversion level of $\sim 60 \%$ for $48-90 \mathrm{~h}$. These activation conditions were chosen based on studies by Bukur et al. that showed that Fe FTS catalysts activated under syngas had lower deactivation rates compared to those activated under $\mathrm{CO}$ and had lower methane selectivity compared to those activated under $\mathrm{H}_{2}[22,23]$. After activation, the reactor conditions were changed to those to be tested, which included temperatures from $220^{\circ} \mathrm{C}$ to $260^{\circ} \mathrm{C}$ and $\mathrm{H}_{2}$ : $\mathrm{CO}$
TABLE 3: Catalyst surface area, pore volume, and average pore diameter.

\begin{tabular}{lccc}
\hline Catalyst & $\begin{array}{c}\text { BET } \\
\text { surface area } \\
\left(\mathrm{m}^{2} / \mathrm{g}\right)\end{array}$ & $\begin{array}{c}\text { Pore volume } \\
\left(\mathrm{cm}^{3} / \mathrm{g}\right)\end{array}$ & $\begin{array}{c}\text { Average pore } \\
\text { diameter } \\
(\mathrm{nm})\end{array}$ \\
\hline $\mathrm{C} 80$ & 71 & 0.155 & 9.8 \\
$\mathrm{C} 100$ & 56 & 0.107 & 8.4 \\
$\mathrm{C} 115$ & 23 & 0.048 & 9.8 \\
$\mathrm{C} 130$ & 54 & 0.203 & 19.4 \\
$\mathrm{C} 130 \mathrm{~b}$ & 87 & 0.163 & 7.9 \\
$\mathrm{C} 150$ & 34 & 0.069 & 8.6 \\
$\mathrm{C} 150 \mathrm{NP}$ & 24 & 0.059 & 13.0 \\
\hline
\end{tabular}

ratios from 0.66 to 1.0. In addition to $\mathrm{CO}$ and $\mathrm{H}_{2}$, the feed gas contained $20-40 \%$ helium used as a diluent to keep the total pressure the same for all runs. The exit gas and liquid effluent passed through a hot trap $\left(110^{\circ} \mathrm{C}\right)$ and a cold trap $\left(0^{\circ} \mathrm{C}\right)$ to collect heavy hydrocarbons and liquid products. The effluent gaseous product was analyzed using an HP 6890 gas chromatograph equipped with a thermal conductivity detector and 60/80 carboxene-1000 column. $\mathrm{CO}$ and $\mathrm{H}_{2}$ conversions and product selectivities were determined with the aid of an Ar tracer.

The rate of reaction (CO depletion) was determined by operating at low $\mathrm{CO}$ conversions $\left(X_{\mathrm{CO}} \leq 0.25\right)$, assuming differential reactor conditions, and thus using the resulting reactor performance equation:

$$
-r_{\mathrm{CO}}=\frac{F_{\mathrm{CO}}^{0} X_{\mathrm{CO}}}{W_{\mathrm{cat}}},
$$

where $W_{\text {cat }}$ is the mass of catalyst and $F_{\mathrm{CO}}^{0}$ is the inlet molar $\mathrm{CO}$ flow rate.

\section{Results}

3.1. Drying Mass Loss. Table 2 shows the mass loss for all catalysts during drying. The mass loss of the catalysts during drying generally increased as final drying temperature increased, ranging from 39.3 to $55.5 \%$, which is higher than the expected mass loss due only to water evaporation (34.4\%). The additional mass loss appeared to be due to loss of ammonium nitrate, which is a byproduct of the SDP reaction, which was observed to seep out of the samples and crystallize as water evaporated, especially for the catalysts dried at higher temperatures.

3.2. Pore Properties. Table 3 summarizes the pore properties of the catalysts obtained from nitrogen adsorption. Surface areas for the reduced catalysts ranged from 23 to $87 \mathrm{~m}^{2} / \mathrm{g}$. Catalyst C115 had the smallest surface area, while catalyst $\mathrm{C} 130 \mathrm{~b}$ had the largest. Pore volumes ranged from 0.048 to $0.203 \mathrm{~cm}^{3} / \mathrm{g}$, with catalyst $\mathrm{C} 130$ having the highest and catalyst $\mathrm{C} 115$ with the lowest.

Figure 1 shows the pore size distributions of the catalysts obtained using a recently reported model assuming slit pore 


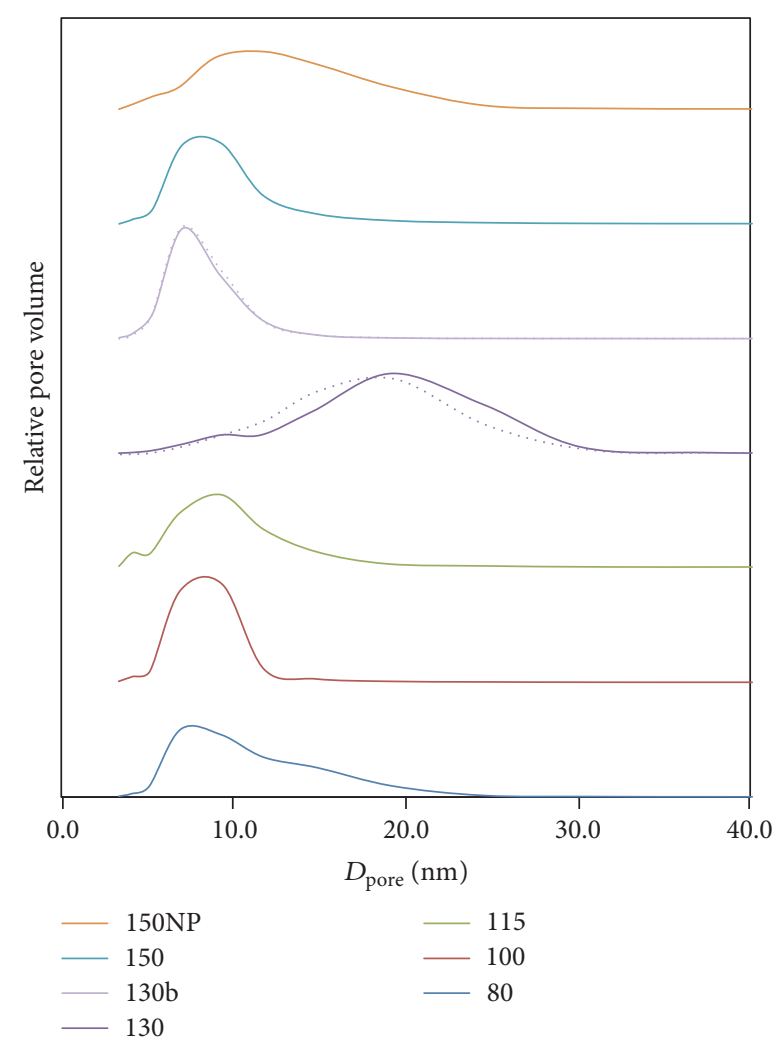

FIGURE 1: Pore size distribution of reduced catalysts (dashed line shows repeat analysis of 130 and $130 \mathrm{~b}$ ).

geometry [21]. Catalyst $\mathrm{C} 130$ has broad peak centered around $20 \mathrm{~nm}$, whereas all of the other catalysts average pore sizes are in the range of 5-14 $\mathrm{nm}$.

The catalysts could arbitrarily be grouped into two categories: high surface area and pore volume (C80, C100, C130, and $\mathrm{C} 130 \mathrm{~b}$ ) and lower surface area and pore volume (C115, $\mathrm{C} 150$, and $\mathrm{C} 150 \mathrm{NP})$. While there is no monotonic trend between drying temperature and surface area, pore volume, or diameter, catalyst $\mathrm{C} 130$ had the highest pore volume, largest diameter, and third highest surface area.

3.3. Temperature Programmed Characterizations. Figure 2 shows the TPR profiles of all catalysts. Two peaks of mass loss were observed, with the first centered roughly at $205-250^{\circ} \mathrm{C}$, while the second is broad and asymmetric, beginning around $300^{\circ} \mathrm{C}$ with maxima at $450-490^{\circ} \mathrm{C}$. The first peak is likely the reduction of hematite $\left(\mathrm{Fe}_{2} \mathrm{O}_{3}\right)$ to magnetite $\left(\mathrm{Fe}_{3} \mathrm{O}_{4}\right)$ [24]; as Yin and Datye have shown, the peak of this low temperature reduction of iron in similar catalysts can occur at $250^{\circ} \mathrm{C}$. The second peak is attributed with further reduction of $\mathrm{Fe}_{3} \mathrm{O}_{4}$ to $\mathrm{FeO}$ and metallic iron $[23,24]$. The ratio of the area of the first peak to that of the second peak is approximately $1: 3$, which is consistent with the oxygen loss from $\mathrm{Fe}_{2} \mathrm{O}_{3}$ to $\mathrm{Fe}_{3} \mathrm{O}_{4}$ and then to a mixture of $\mathrm{FeO}$ and $\mathrm{Fe}$ because the catalysts are not fully reduced (see the extent of reduction (EOR) discussion next). Catalysts C130, C130b, and C110 are the most difficult to reduce, as indicated by the highest reduction temperatures.

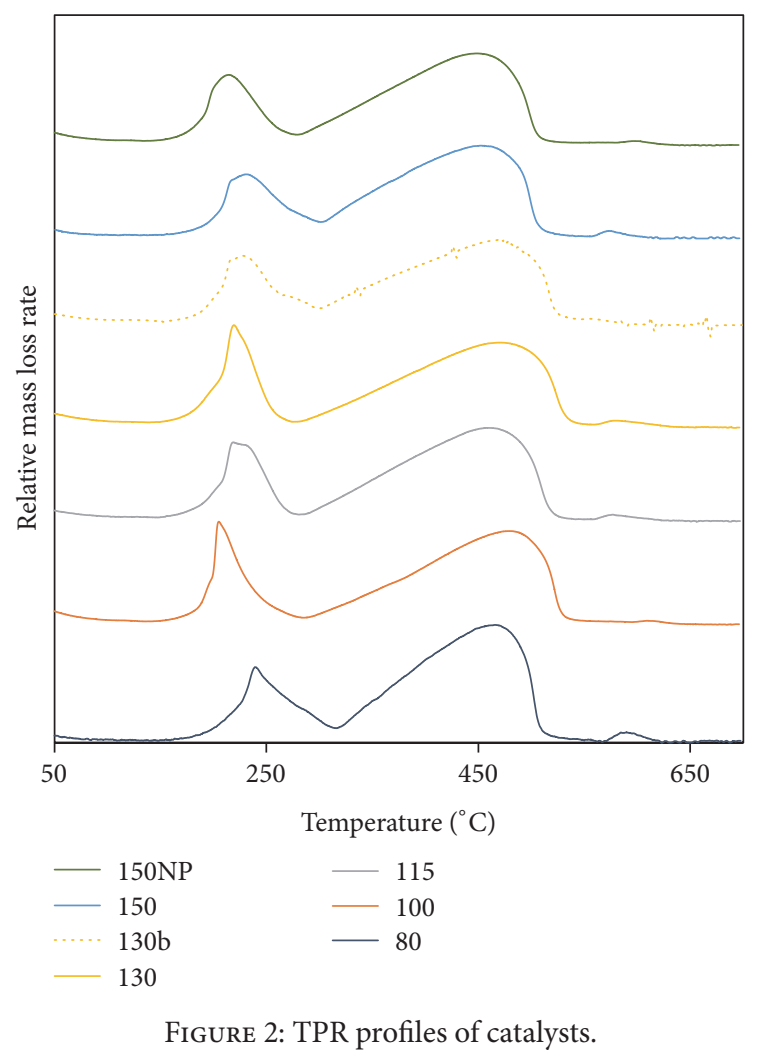

TABLE 4: Catalyst extent of reduction (EOR), calculated by oxygen titration.

\begin{tabular}{lcc}
\hline Catalyst name & EOR & $\mathrm{O}_{2}$ uptake $(\mathrm{mmol} / \mathrm{g})$ \\
\hline C80 & $30.0 \%$ & 5.71 \\
C100 & $23.5 \%$ & 4.47 \\
C115 & $30.0 \%$ & 5.71 \\
C130 & $43.0 \%$ & 8.17 \\
C130b & $32.9 \%$ & 6.26 \\
C150 & $7.7 \%$ & 1.46 \\
C150NP & $13.8 \%$ & 2.61 \\
\hline
\end{tabular}

Iron undergoes a unique reduction process involving several intermediate possibilities from the fully oxidized $\mathrm{Fe}_{2} \mathrm{O}_{3}, \mathrm{Fe}_{3} \mathrm{O}_{4}, \mathrm{FeO}$, and $\mathrm{Fe}$. The EOR was calculated by taking the actual oxygen uptake after reduction divided by the maximum theoretical oxygen uptake, assuming all $\mathrm{Fe}$ was initially $\mathrm{Fe}_{2} \mathrm{O}_{3}$. The results for EOR are shown in Table 4. The EOR is roughly $33 \%$, which is consistent with the oxygen mass loss obtained from the TPR data (Figure 2). Once again, C130 is markedly different than the other catalysts. The highest EOR were observed for $\mathrm{C} 130$ and C130b. C150 and C150NP had the lowest oxygen uptakes and therefore the lowest EOR.

TPOs were performed to detect the phase transitions of the ammonium nitrates in the dried samples. A typical differential scanning calorimetry heat curve is shown in Figure 3 for catalyst C115. The first small peak around $84^{\circ} \mathrm{C}$ is attributed to the $\mathrm{NH}_{4} \mathrm{NO}_{3}$ structural transformation from phase I (orthorhombic) to phase II (tetragonal). The phase II to phase III transition (occurring at $\sim 125^{\circ} \mathrm{C}$ ), melting (at 


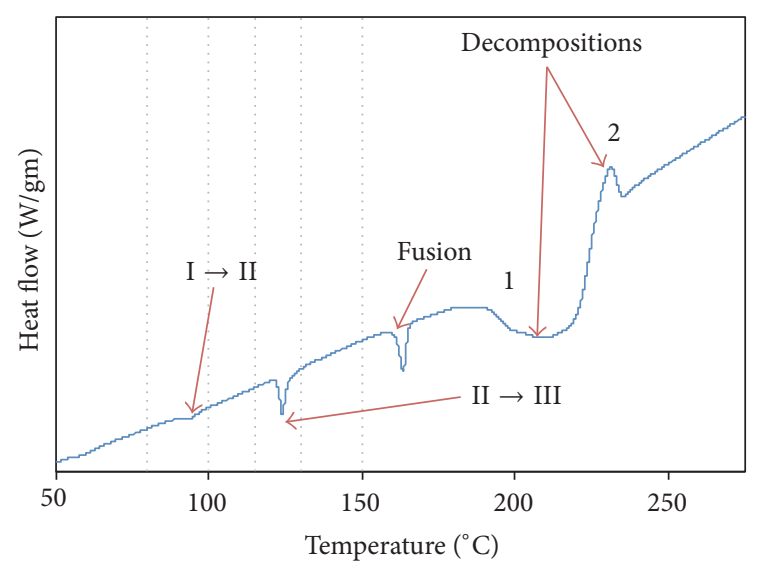

FIGURE 3: Differential scanning calorimetry heat flow curve during oxidation of catalyst 115, showing ammonium nitrate phase transitions. Dashed vertical lines show the final drying temperatures for the various catalysts.

TABLE 5: Peak temperatures for ammonium nitrate phase transitions, melting, and decomposition of different catalysts during TPO.

\begin{tabular}{lcccc}
\hline $\begin{array}{l}\text { Catalyst } \\
\text { name }\end{array}$ & II $\rightarrow$ III $\left({ }^{\circ} \mathrm{C}\right)$ & Melting $\left({ }^{\circ} \mathrm{C}\right)$ & \multicolumn{2}{c}{ Decomposition $(1 \& 2)\left({ }^{\circ} \mathrm{C}\right)$} \\
\hline C80 & 120.7 & 159.8 & 206.6 & 223.5 \\
C100 & 124.0 & 163.1 & 215.4 & 230.8 \\
C115 & 123.9 & 163.1 & 213.1 & 228.0 \\
C130 & 123.8 & 163.3 & 216.4 & 231.1 \\
C130b & 127.7 & 161.8 & 214.4 & 231.9 \\
C150 & 123.5 & 163.3 & 219.7 & 233.3 \\
C150NP & 124.1 & 163.7 & 212.6 & 229.3 \\
\hline
\end{tabular}

$\sim 169^{\circ} \mathrm{C}$ ), and decomposition peaks (at $\sim 215^{\circ} \mathrm{C}$ and $\sim 230^{\circ} \mathrm{C}$ ) are the most prominent, with corresponding temperatures for each catalyst listed in Table 5. All catalysts had very similar temperatures for ammonium nitrate transitions, except for 80, which had transitions at anywhere from 3 to $10^{\circ} \mathrm{C}$ lower than the others. Catalyst C130b also had a slightly higher phase II to phase III transition and a slightly lower fusion temperature.

Although the active phase for iron Fischer-Tropsch is widely accepted as iron carbide [25], CO uptake experiments on the reduced catalysts were performed on all catalysts in order to estimate the initial number of sites available for $\mathrm{CO}$ adsorption for carbidization. As shown in Figure 4, catalyst C130 shows the highest CO uptake, whereas catalysts C150NP, $\mathrm{C} 115$, and $\mathrm{C} 150$ had the lowest uptakes.

3.4. XRD Results. Figure 5 shows XRD patterns of the reduced, passivated catalysts. Particle sizes calculated from the Scherrer equation, based on the intensity of the peaks for both $\mathrm{Fe}$ and $\mathrm{Fe}_{3} \mathrm{O}_{4}$, are listed in Table 6. Once again, catalyst $\mathrm{C} 130$ was unusual. Catalyst C130, both initially and during replicate experiment $\mathrm{Cl} 30 \mathrm{r}$, showed clear peaks of $\mathrm{Fe}$, while the other catalysts showed characteristic peaks of $\mathrm{Fe}_{3} \mathrm{O}_{4}$, suggesting that the reduced and passivated sample of catalysts

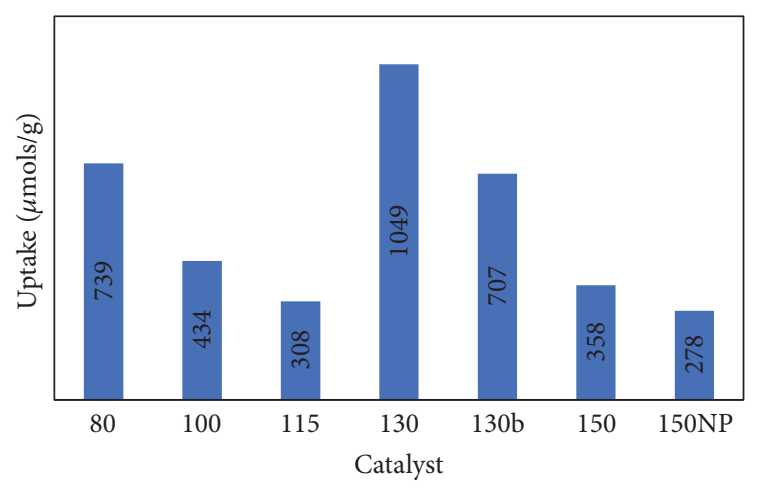

FIgURE 4: CO uptake.

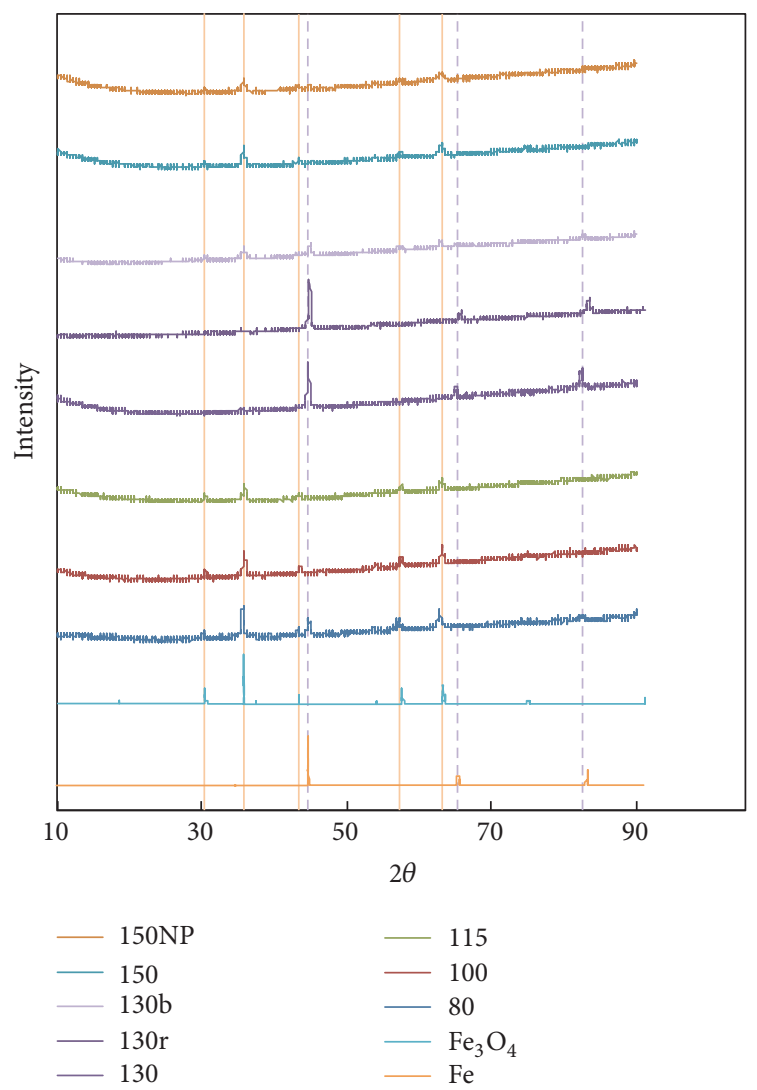

FIGURE 5: XRD patterns of each catalyst (dashed vertical lines show Fe peaks; solid vertical lines show $\mathrm{Fe}_{3} \mathrm{O}_{4}$ peaks).

C130 contained no significant $\mathrm{Fe}_{3} \mathrm{O}_{4}$ phase. Catalysts C100, $\mathrm{C} 115$, and $\mathrm{C} 150$ did not show peaks for Fe metal. This may be because the iron domains were too small to be detected by XRD. $\mathrm{Fe}_{3} \mathrm{O}_{4}$ crystallite sizes ranged from 16.6 to $24.5 \mathrm{~nm}$ and $\mathrm{Fe}$ crystallite sizes ranged from 19.5 to $33.1 \mathrm{~nm}$. Catalyst $\mathrm{C} 150$ had the smallest $\mathrm{Fe}_{3} \mathrm{O}_{4}$ crystallite size and the largest $\mathrm{Fe}$ crystallite size. Conversely, C80 had the smallest Fe crystallite size and the largest $\mathrm{Fe}_{3} \mathrm{O}_{4}$ size.

3.5. FTS Rate and Selectivity. Rate and selectivity data for the Fischer-Tropsch reaction were obtained via the fixed-bed 
TABLE 6: XRD crystallite size.

\begin{tabular}{lcc}
\hline Catalyst & \multicolumn{2}{c}{ Crystallite size $(\mathrm{nm})$} \\
Name & $\mathrm{Fe}_{3} \mathrm{O}_{4}$ & $\mathrm{Fe}$ \\
\hline $\mathrm{C} 80$ & 24.5 & 19.5 \\
$\mathrm{C} 100$ & 22.7 & - \\
$\mathrm{C} 115$ & 18.6 & - \\
$\mathrm{C} 130$ & - & 22.2 \\
$\mathrm{C} 130 \mathrm{r}$ & - & 31 \\
$\mathrm{C} 130 \mathrm{~b}$ & 22.6 & 23.2 \\
$\mathrm{C} 150$ & 20.9 & - \\
$\mathrm{C} 150 \mathrm{NP}$ & 16.6 & 33.1 \\
\hline
\end{tabular}

reactor for all catalysts. Temperatures in the reactor ranged from 230 to $260^{\circ} \mathrm{C}$, with the longest runs lasting around $220 \mathrm{~h}$. In general, the catalysts were tested at $250^{\circ} \mathrm{C}$ both at the start and at the end of each experiment in order to determine the stability of the catalyst. Results of these runs are shown in Table 7.

Figure 6 contains an Arrhenius representation of the rate data. Catalysts $\mathrm{C} 130$ and $\mathrm{C} 130 \mathrm{~b}$ show very similar rates, while C130r has rates that are somewhat higher, which is an indication of the reproducibility of the FTS experimental runs.

For direct comparison, Table 8 summarizes the rate of $\mathrm{CO}$ consumption for all catalysts at $250^{\circ} \mathrm{C}$, as well as the activation energy and preexponential factors calculated from the data in Figure 6.

For all catalysts, their rates ranged from 34.6 to $47.2 \mathrm{mmol}$ $\mathrm{CO} / \mathrm{g} / \mathrm{h}$ and their methane selectivity ranged from 3.07 to $6.11 \%$. The best catalysts, which are those dried at $130^{\circ} \mathrm{C}$, exhibited the highest $\mathrm{CO}$ reaction rate and the lowest $\mathrm{CH}_{4}$ selectivity. The reproducibility of catalyst $\mathrm{C} 130$ was confirmed in the case of Fischer-Tropsch performance, as $\mathrm{Cl30}$, the same sample rerun in the fixed-bed (C130r), and the remake (C130b) performed well, with similar rates and selectivities.

\section{Discussion}

4.1. Ferrihydrite Agglomeration. The SDP method using iron salts produces ferrihydrite [26]. These ferrihydrite particles have been hypothesized to agglomerate due to hydroxyl groups and water. The surface hydroxyl groups tend to hydrogen bond with each other to form weak linkages, as described by Brunner (K. M. Brunner Doctor of Philosophy, Brigham Young University, 2012), similar to the formation of layered structures during the transition from boehmite to $\gamma$-alumina [27]. The ammonium nitrate ions were hypothesized to interact with the surface hydroxyl groups of the ferrihydrite, thus interfering with the formation of weak linkages and preventing further agglomeration, as shown schematically in Figure 7.

4.2. Observed Phase Transition Effects. Catalysts C130 and $\mathrm{C} 130 \mathrm{~b}$ are the most active and have better catalytic properties overall, despite their occasional differences, when compared with the rest of the catalysts. The likely explanation is the ammonium nitrate phase transition that occurs near the drying temperature of these catalysts. Phase III for ammonium nitrate is a cubic structure, whereas phase II is a tetragonal structure [20]. This phase change in crystal structure may explain catalyst C130's increased pore volume, high surface area, better rate, and selectivity, as shown in Scheme 1. If this is the case, the iron oxide could have formed a layer around the ammonium nitrate in the tetragonal phase, which is disrupted during the drying process as it transforms to the cubic phase, as shown in Table 1 . Then, during calcination, the ammonium nitrate melts and decomposes, thus leaving the iron oxide frozen in a disrupted structure that has a higher volume pore that leads to better catalytic performance. Even the variability among the physical properties of the two $\mathrm{C} 130$ catalysts is likely associated with this phase transition and the associated instability associated with it. However, as previously noted, the catalytic properties of all $\mathrm{C} 130$ catalysts are superior to the catalysts dried at other temperatures. This sensitivity to the precise drying conditions is further emphasized by the C150 and C150NP catalysts, which displayed low pore volumes, despite passing through the same AN phase transitions as $\mathrm{C} 130$ and $\mathrm{C} 130 \mathrm{~b}$, which presumably should result in the same favorable conditions. However, higher drying temperatures are associated with faster drying rates, which might have affected the development of the optimal pore structure, through either surface tension and capillary effects as the residual solvent water left the structure or the formation of a more defective structure because the faster drying rate did not allow time for a more ordered crystalline structure to be set in place.

Higher drying temperatures led to lower surface area, pore volume, and CO uptake until the II to III ammonium nitrate phase transition, at which point these values jumped and then resumed their declining trends as drying temperature increased. These trends are shown in Figures 8 and 9.

A similar trend between drying temperature and catalytic rate was observed during the FTS reaction. Catalysts C130 and $\mathrm{C} 130 \mathrm{~b}$ had the highest rate, while catalysts $\mathrm{C} 150$ and C150NP performed relatively poorly, although both sets of catalysts presumably experienced the same phase transitions and had the same phase (III) of ammonium nitrate present after drying. As discussed previously, this is proposed to be explained by two counteracting effects. The first is that higher temperatures, and thus higher drying rates, generally produce pore structures within the catalysts that lead to poorer catalyst activity. The second is that the ammonium nitrate phase transitions which occur during drying interrupts this general downward trend in catalytic rate as a function of temperature by introducing two distinct step changes in activity. As shown in Figure 10, which graphs the FTS rate of each catalyst at $250^{\circ} \mathrm{C}, \sim 20.5 \mathrm{MPa}$, and $1: 1 \mathrm{H}_{2}: \mathrm{CO}$ as a function of drying temperature, catalyst C80, dried in the presence of phase I ammonium nitrate, forms a structure that is less active than catalyst $\mathrm{C} 100$, which was dried just above the phase I to phase II transition temperature. However, catalyst C115, dried well above the phase I to phase II transition temperature, has similar rate to catalyst C80. Similarly, the catalysts ( $\mathrm{C} 130$ and $\mathrm{C} 130 \mathrm{~b})$ dried in the presence of phase 
TABLE 7: Catalytic performance of different catalysts during fixed-bed reactor runs.

\begin{tabular}{|c|c|c|c|c|c|c|c|}
\hline Catalyst name & Time on stream (h) & $T\left({ }^{\circ} \mathrm{C}\right)$ & $-r_{\mathrm{co}}(\mathrm{mmol} / \mathrm{g} / \mathrm{h})^{\mathrm{a}}$ & $X_{\mathrm{CO}}{ }^{\mathrm{b}}$ & $\mathrm{CH}_{4}(\%)$ & $\mathrm{CO}_{2}(\%)$ & $C_{2+}(\%)^{c}$ \\
\hline \multirow{4}{*}{$\mathrm{C} 80$} & 75 & 250 & 35.1 & 0.235 & 3.65 & 46.7 & 49.7 \\
\hline & 83 & 240 & 22.4 & 0.150 & 3.48 & 43.8 & 52.8 \\
\hline & 92 & 259 & 63.3 & 0.200 & 4.03 & 46.3 & 49.6 \\
\hline & 107 & 249 & 37.2 & 0.252 & 3.76 & 46.2 & 50.0 \\
\hline \multirow{4}{*}{$\mathrm{C} 100$} & 95 & 250 & 40.9 & 0.160 & 6.11 & 44.5 & 49.4 \\
\hline & 131 & 230 & 16.1 & 0.063 & 5.51 & 36.8 & 57.7 \\
\hline & 152 & 260 & 69.4 & 0.173 & 6.64 & 46.0 & 47.4 \\
\hline & 180 & 240 & 26.9 & 0.067 & 6.13 & 39.3 & 54.6 \\
\hline \multirow{4}{*}{ C115 } & 75 & 251 & 36.3 & 0.219 & 4.50 & 44.2 & 51.3 \\
\hline & 83 & 241 & 24.1 & 0.145 & 4.17 & 40.9 & 54.9 \\
\hline & 96 & 260 & 60.1 & 0.171 & 5.19 & 43.5 & 51.3 \\
\hline & 107 & 250 & 37.3 & 0.225 & 4.62 & 43.9 & 51.5 \\
\hline \multirow{4}{*}{$\mathrm{C} 130$} & 88 & 250 & 47.2 & 0.175 & 3.46 & 43.4 & 53.1 \\
\hline & 131 & 230 & 20.7 & 0.077 & 3.08 & 36.9 & 60.0 \\
\hline & 153 & 260 & 79.0 & 0.194 & 3.67 & 44.3 & 52.0 \\
\hline & 212 & 240 & 25.9 & 0.064 & 3.26 & 36.1 & 60.7 \\
\hline \multirow{4}{*}{$\mathrm{C} 130 \mathrm{r}$} & 64 & 250 & 52.7 & 0.220 & 3.02 & 42.4 & 54.6 \\
\hline & 74 & 240 & 35.3 & 0.147 & 2.82 & 39.0 & 58.2 \\
\hline & 87 & 260 & 85.4 & 0.200 & 3.41 & 42.9 & 53.7 \\
\hline & 98 & 249 & 57.4 & 0.240 & 3.12 & 42.5 & 54.4 \\
\hline \multirow{4}{*}{$\mathrm{C} 130 \mathrm{~b}$} & 64 & 250 & 46.9 & 0.220 & 3.21 & 42.5 & 54.3 \\
\hline & 73 & 240 & 30.6 & 0.143 & 3.01 & 39.3 & 57.7 \\
\hline & 86 & 260 & 76.9 & 0.185 & 3.67 & 42.9 & 53.4 \\
\hline & 98 & 250 & 50.0 & 0.235 & 3.33 & 42.7 & 54.0 \\
\hline \multirow{4}{*}{$\mathrm{C} 150$} & 57 & 255 & 40.6 & 0.203 & 5.34 & 44.7 & 49.9 \\
\hline & 79 & 246 & 26.0 & 0.130 & 5.17 & 42.0 & 52.8 \\
\hline & 104 & 260 & 52.0 & 0.140 & 6.07 & 43.5 & 50.4 \\
\hline & 121 & 251 & 34.6 & 0.093 & 5.79 & 40.0 & 54.3 \\
\hline \multirow{4}{*}{ C150NP } & 57 & 257 & 45.7 & 0.219 & 4.27 & 43.3 & 52.4 \\
\hline & 77 & 247 & 30.1 & 0.144 & 4.02 & 40.7 & 55.3 \\
\hline & 103 & 261 & 53.7 & 0.138 & 5.08 & 41.9 & 53.1 \\
\hline & 120 & 252 & 37.8 & 0.097 & 4.64 & 38.8 & 56.6 \\
\hline
\end{tabular}

${ }^{\mathrm{a}} \mathrm{CO}$ consumption rate; ${ }^{\mathrm{b}} \mathrm{CO}$ conversion; ${ }^{\mathrm{c}}$ Products heavier than methane.

III ammonium nitrate, just above the phase II to phase III transition temperature, form a structure that is more active than that dried far above the phase II to phase III transition temperature. Interestingly, catalysts C80, C115, and C150 all produce approximately the same, relatively low rates, while the catalysts dried at temperatures nearest to the ammonium nitrate phase transitions, $\mathrm{C} 100$ and $\mathrm{C130}$, produce higher rates, although all $\mathrm{C} 130$ catalysts are superior. The error bars in the figures represent $95 \%$ confidence intervals of the reported data.

4.3. Reaction Rate Correlations. A positive correlation was found between EOR, calculated via the $\mathrm{O}_{2}$ titration method, and the FTS rate (see Figure 11). A similar positive correlation was found between $\mathrm{CO}$ uptake and rate (see Figure 12). Although the correlation is not strong, general trends can still be observed. Increasing reaction rate with increasing $\mathrm{CO}$ uptake is consistent with the requirement for $\mathrm{CO}$ to adsorb on the catalyst surface prior to reaction. The correlation of rate with extent of reduction is likely associated with the ability of the catalyst surface to accept electrons, as required for facile catalytic turnovers.

4.4. Reproducibility. Catalysts $\mathrm{C} 130$ and $\mathrm{C} 130 \mathrm{~b}$ produced similar rate and selectivity results during the FTS catalytic experiments, which supports the reproducibility of the results reported in this study. However, catalysts C130 and C130b had some widely different physical characteristics between the two and also compared to the other catalysts in the series. For example, C130b had a much higher surface area $\left(87 \mathrm{~m}^{2} / \mathrm{g}\right)$ and $\mathrm{C} 130$ had a much larger pore volume $\left(0.203 \mathrm{~cm}^{3} / \mathrm{g}\right)$ and average pore diameter $(20.2 \mathrm{~nm})$ compared to any of the other catalysts. Both also had high EOR and CO uptakes, although C130b was slightly lower than C130 in both cases. Perhaps the most distinct difference between the two was 


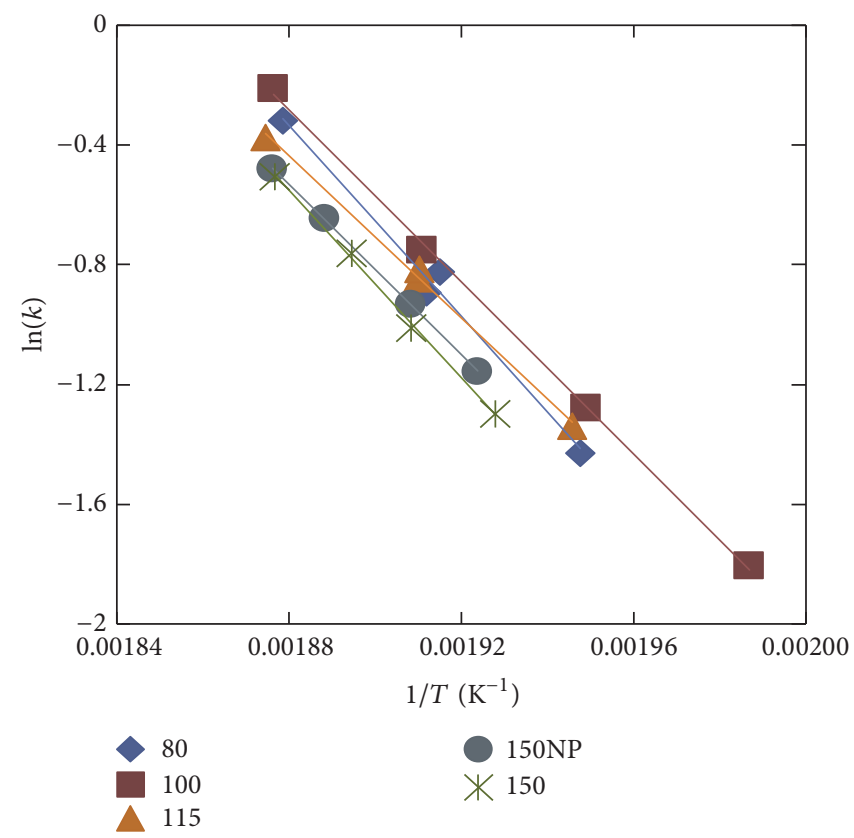

(a)

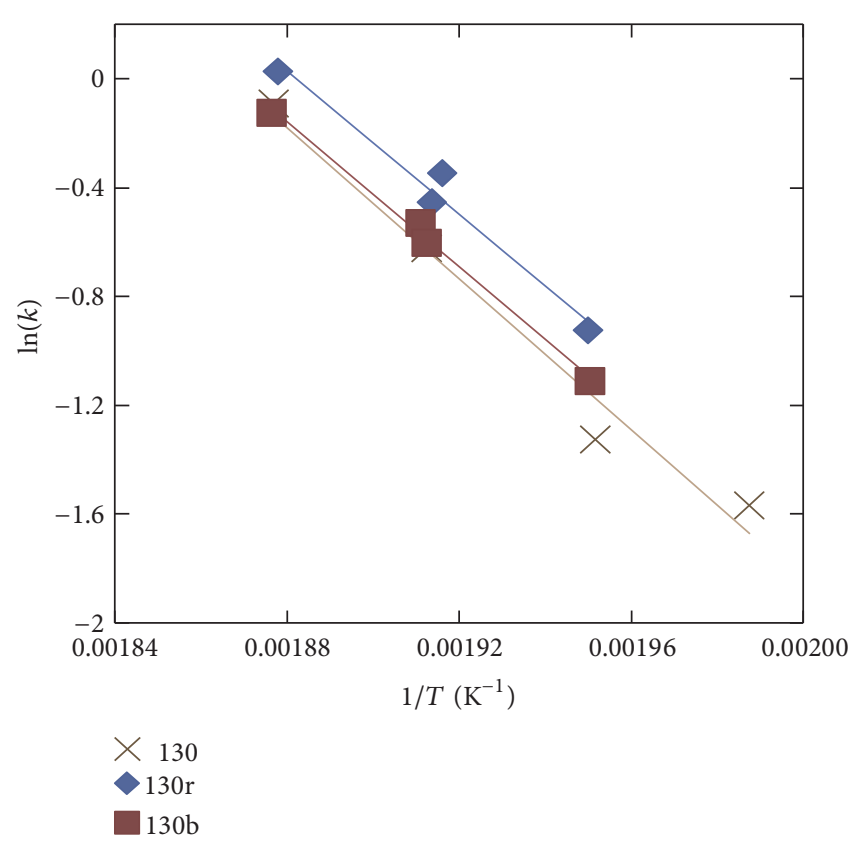

(b)

FIGURE 6: Arrhenius plots for each catalyst. Plot (a) includes catalysts 80, 100, 115, 150, and 150NP. Plot (b) includes catalysts 130, 130b, and 130 r.

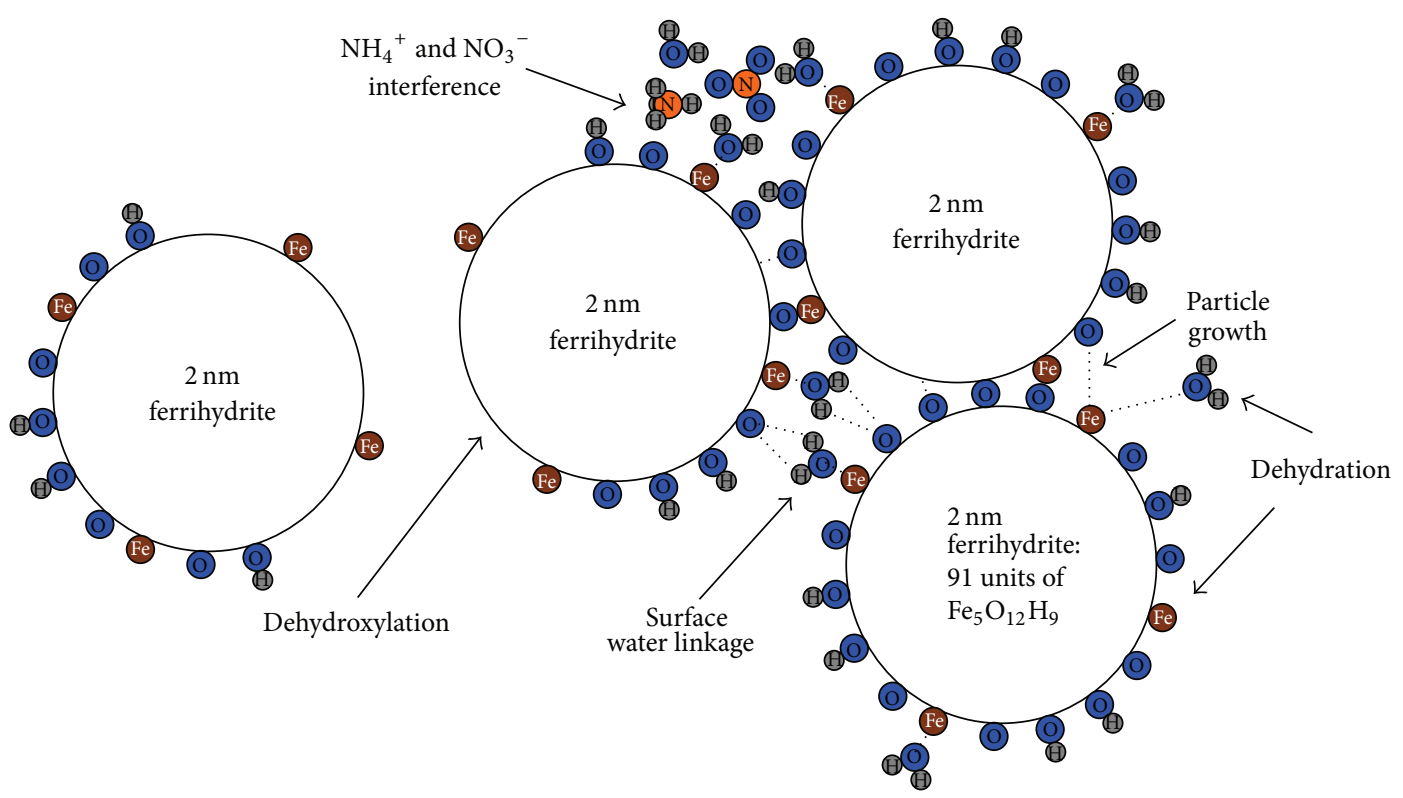

FIGURE 7: Ferrihydrite agglomeration theory as proposed by Brunner (K. M. Brunner Doctor of Philosophy, Brigham Young University, 2012). (Atoms are shown in different colors: blue $=\mathrm{O}$, grey $=\mathrm{H}$, and orange $=\mathrm{N}$.)

shown on the XRD results, where 130 displayed no $\mathrm{Fe}_{3} \mathrm{O}_{4}$ peaks, while $\mathrm{Cl} 130 \mathrm{~b}$ showed both $\mathrm{Fe}_{3} \mathrm{O}_{4}$ and $\mathrm{Fe}$ peaks. Despite these differences, both performed similarly as FTS catalysts.

These physical differences between two samples prepared by identical methods suggest that minor variations in drying conditions, such as sample thickness or air flow uniformity, may lead to significant variation in the physical characteristics of the catalysts. This may be due to instability in the phase properties or the formation of metastable phases near the transition temperature, similar to those observed during thermodynamic studies of other phase transitions (e.g., fluctuations in properties near the supercritical point 


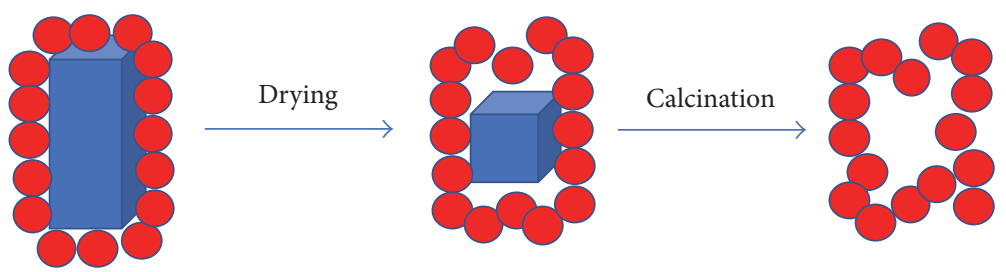

Scheme 1: Pore formation process during drying and calcination. The iron oxide particles (red) are pictured to form a layer around the ammonium nitrate (blue) in the tetragonal phase, which is disrupted during the drying process at appropriate temperatures as it transforms to the cubic phase. Then, during calcination, the ammonium nitrate melts and decomposes, thus leaving the iron oxide frozen in a disrupted structure that has a higher volume pore structure that leads to better catalytic performance.

TABLE 8: CO consumption rate, activation energy, and $\mathrm{CH}_{4}$ selectivity of each catalyst at $250^{\circ} \mathrm{C}$.

\begin{tabular}{lccc}
\hline Catalyst & $\begin{array}{c}\text { CO consumption rate } \\
(\mathrm{mmol} / \mathrm{g} / \mathrm{h})\end{array}$ & $\begin{array}{c}E_{A} \\
(\mathrm{~kJ} / \mathrm{mol})\end{array}$ & $\begin{array}{c}\mathrm{CH}_{4} \text { selectivity } \\
(\%)\end{array}$ \\
\hline C80 & 35.1 & 133 & 3.65 \\
C100 & 40.9 & 119 & 6.11 \\
C115 & 37.3 & 112 & 4.50 \\
C130 & 47.2 & 115 & 3.46 \\
C130r & 52.7 & 109 & 3.07 \\
C130b & 46.9 & 111 & 3.27 \\
C150 & $31.0^{*}$ & 130 & 5.79 \\
C150NP & $33.1^{*}$ & 118 & 4.64 \\
\hline
\end{tabular}

* Rate data at exactly $250^{\circ} \mathrm{C}$ were not available and were obtained using the calculated activation energies and the Arrhenius equation to estimate the $250^{\circ} \mathrm{C}$ values.

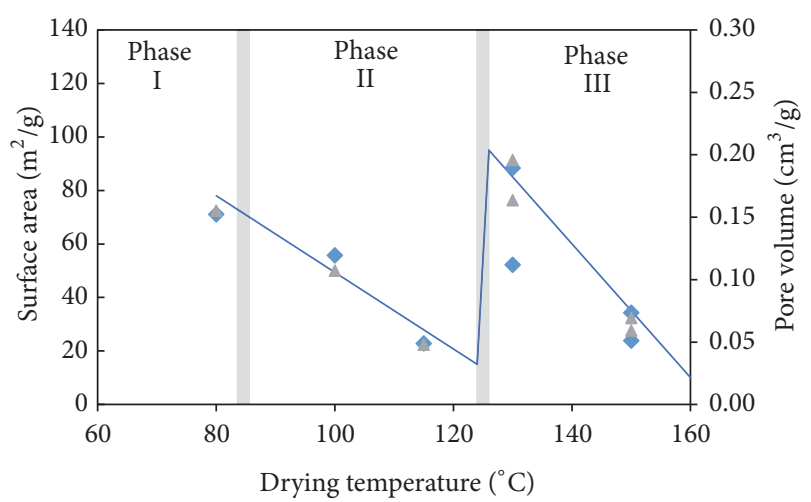

SA
$\triangle \mathrm{PV}$

FIGURE 8: Drying temperature versus surface area (left axis) and pore volume (right axis).

or the region between the spinodal curve and the coexistence/equilibrium curve in partially miscible liquid systems [28]). Despite the resulting physical differences, the catalytic performance was statistically similar, which indicates that drying near the AN phase transition produces superior FTS catalysts, while the relative variability in the physical properties is not as important.

The results of this study point to the need for further care in the drying step of catalyst synthesis, particularly

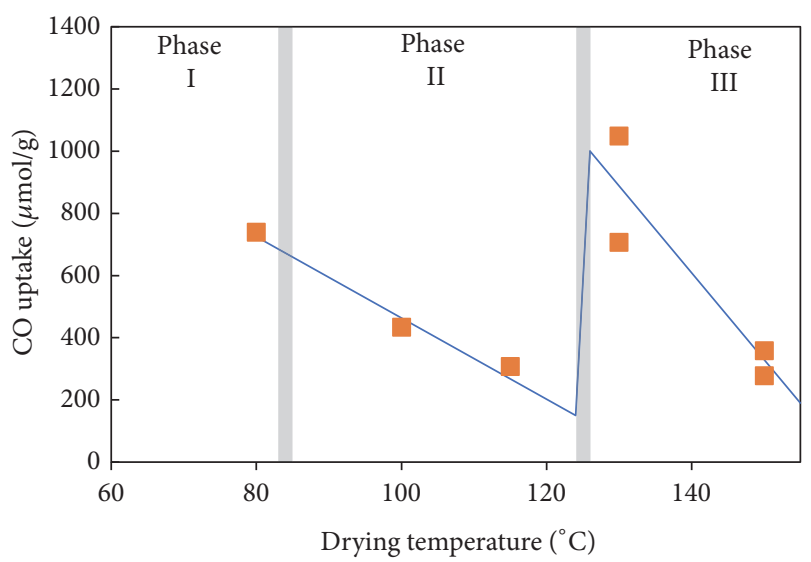

FIgURE 9: Drying temperature versus CO chemisorption uptake. Vertical lines show phase changes of ammonium nitrate.

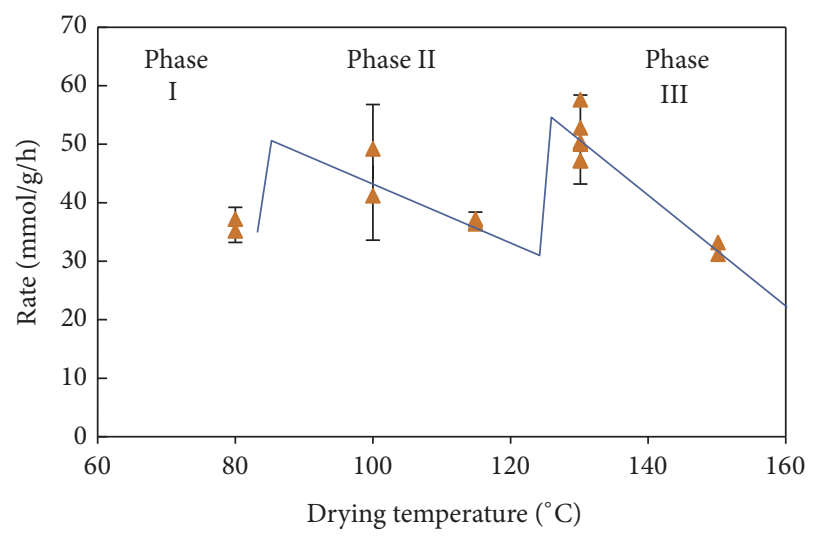

FIGURE 10: Effect of drying temperature on FTS rate at around $250^{\circ} \mathrm{C}\left[\sim 20.5 \mathrm{MPa}\right.$ with $\left.1: 1 \mathrm{H}_{2}: \mathrm{CO}\right]$. Numerical data also available in Table 7. Vertical lines show phase changes of ammonium nitrate.

those made from precursor chemicals that can produce ammonium nitrate in the precursor catalysts prior to thermal treatment or calcination. Many transition metal catalysts studied at the laboratory scale are synthesized using metal nitrate precursors, due to the solubility of the metal nitrates in both aqueous and polar organic solvents, like acetone. If these nitrate solutions are titrated with ammonium hydroxide or other ammonium containing bases during coprecipitation, 


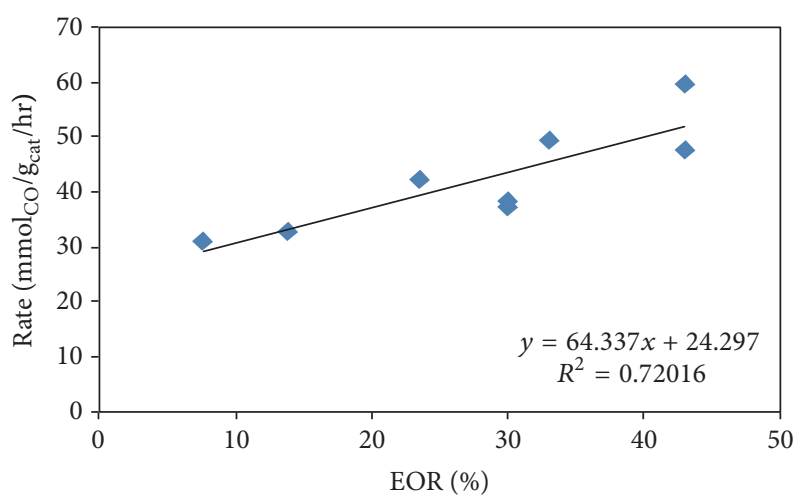

FIGURE 11: Catalyst extent of reduction (EOR) relative to $\mathrm{Fe}_{2} \mathrm{O}_{3}(0 \%)$ and $\mathrm{Fe}^{0}(100 \%)$ versus Fischer-Tropsch synthesis rate.

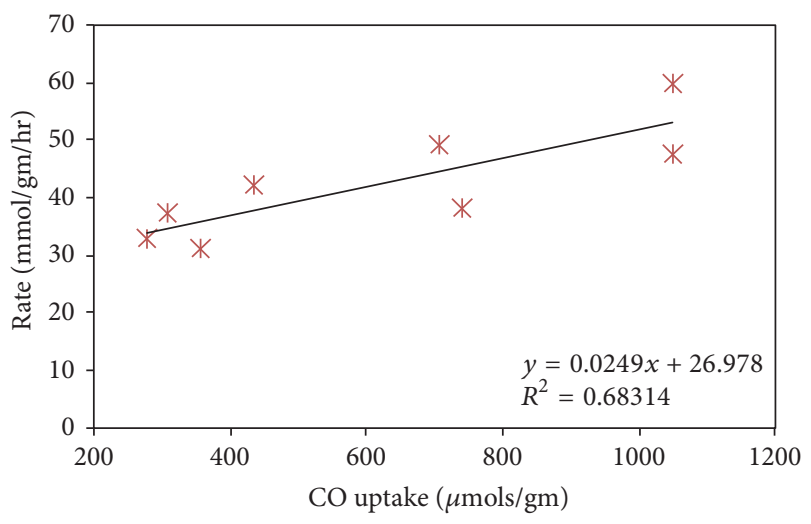

FIGURE 12: CO uptake versus Fischer-Tropsch synthesis rate.

the resultant ammonium nitrate salt in the dried catalyst can exhibit the phase behavior and the significant variations in catalytic performance reported in this work. The only difference among these catalysts was the low temperature drying step, which was conducted between $80^{\circ} \mathrm{C}$ and $150^{\circ} \mathrm{C}$. Otherwise, the catalysts were prepared identically. The wide variability in final physical, chemical, and catalytic properties of the materials points to the need for careful evaluation and control during the drying step.

\section{Conclusion}

Fischer-Tropsch synthesis (FTS) catalysts prepared by the solvent deficient precipitation (SDP) method and dried at $130^{\circ} \mathrm{C}$ have higher pore volume, surface area, extent of reduction (EOR), and FTS rate and lower methane selectivity compared to identical catalysts dried at higher or lower temperatures. Further, XRD analysis showed that there were less or no $\mathrm{Fe}_{3} \mathrm{O}_{4}$ and significant $\mathrm{Fe}^{0}$ present in the catalysts dried at $130^{\circ} \mathrm{C}$ compared to these other catalysts. With the exception of the catalysts dried at $130^{\circ} \mathrm{C}$, higher drying temperature, with a concomitant higher drying rate, leads to worse catalytic properties in the form of lower catalyst surface area, smaller pore volume, and lower $\mathrm{CO}$ uptake. However, there is a benefit to drying at a higher temperature for the C110 and
C130 catalysts, presumably due to the ammonium nitrate phase transitions during drying between phase I and phase II and between phase II and phase III ammonium nitrate. The catalysts dried at a $130^{\circ} \mathrm{C}$ generally have the best rate and physical characteristics. The results of this work indicate that more attention should be paid to drying conditions during catalyst synthesis, particularly for those catalysts formed from precursor chemicals which create ammonium nitrate.

\section{Conflicts of Interest}

The authors declare that there are no conflicts of interest regarding the publication of this paper.

\section{Acknowledgments}

The authors wish to acknowledge the contributions of Johnathon Horton, Brad Chandler, and Dane Bennion for their assistance during the experimental portion of this work. The members of the BYU Fischer-Tropsch Consortium provided funding.

\section{References}

[1] C. H. Bartholomew and R. J. Farrauto, Fundamentals of Industrial Catalytic Processes, Wiley, 2011.

[2] M. G. A. Cruz, M. Bastos-Neto, A. C. Oliveira et al., "On the structural, textural and morphological features of Fe-based catalysts supported on polystyrene mesoporous carbon for Fischer-Tropsch synthesis," Applied Catalysis A: General, vol. 495, pp. 72-83, 2015.

[3] A. Griboval-Constant, A. Butel, V. V. Ordomsky, P. A. Chernavskii, and A. Y. Khodakov, "Cobalt and iron species in alumina supported bimetallic catalysts for Fischer-Tropsch reaction," Applied Catalysis A: General, vol. 481, pp. 116-126, 2014.

[4] H. Schulz, Fischer-Tropsch Synthesis in a Modern Perspective, Wiley-VCH Verlag GmbH \& Co. KGaA, 2012.

[5] A. P. Steynberg, Fischer-Tropsch Technology, vol. 152, 2004.

[6] C. Perego and P. Villa, "Catalyst preparation methods," Catalysis Today, vol. 34, no. 3-4, pp. 281-305, 1997.

[7] M. Campanati, G. Fornasari, and A. Vaccari, "Fundamentals in the preparation of heterogeneous catalysts," Catalysis Today, vol. 77, no. 4, pp. 299-314, 2003.

[8] A. Lekhal, B. J. Glasser, and J. G. Khinast, Catalyst Preparation: Science and Engineering, vol. 375, 2007.

[9] X. Liu, J. G. Khinast, and B. J. Glasser, "A parametric investigation of impregnation and drying of supported catalysts," Chemical Engineering Science, vol. 63, no. 18, pp. 4517-4530, 2008.

[10] A. J. Van Dillen, R. J. A. M. Terörde, D. J. Lensveld, J. W. Geus, and K. P. De Jong, "Synthesis of supported catalysts by impregnation and drying using aqueous chelated metal complexes," Journal of Catalysis, vol. 216, no. 1-2, pp. 257-264, 2003.

[11] G. B. Raupp and W. N. Delgass, "Mössbauer investigation of supported Fe and FeNi catalysts. I. Effect of pretreatment on particle size," Journal of Catalysis, vol. 58, no. 3, pp. 337-347, 1979.

[12] T. Toupance, M. Kermarec, and C. Louis, "Metal particle size in silica-supported copper catalysts. influence of the conditions 
of preparation and of thermal pretreatments," The Journal of Physical Chemistry B, vol. 104, pp. 965-972, 2000.

[13] C. Chouillet, F. Villain, M. Kermarec, H. Lauron-Pernot, and C. Louis, "Relevance of the drying step in the preparation by impregnation of $\mathrm{Zn} / \mathrm{SiO}_{2}$ supported catalysts," The Journal of Physical Chemistry B, vol. 107, pp. 3565-3575, 2003.

[14] T. M. Eggenhuisen, P. Munnik, H. Talsma, P. E. De Jongh, and K. P. De Jong, "Freeze-drying for controlled nanoparticle distribution in $\mathrm{Co} / \mathrm{SiO} 2$ Fischer-Tropsch catalysts," Journal of Catalysis, vol. 297, pp. 306-313, 2013.

[15] S. Liu, Q. Liu, J. Boerio-Goates, and B. F. Woodfield, vol. 39, pp. 18-23, 2007.

[16] C. H. Bartholomew, B. F. Woodfield, B. Huang, R. E. Olsen, and L. Astle, Google Patents, 2011.

[17] United States Patent, 8,211,388.

[18] K. M. Brunner, G. E. Harper, K. Keyvanloo, B. F. Woodfield, C. H. Bartholomew, and W. C. Hecker, "Preparation of an unsupported iron fischer-tropsch catalyst by a simple, novel, solvent-deficient precipitation (SDP) method," Energy \& Fuels, vol. 29, no. 3, 2015, 150215152253009.

[19] C. Oommen and S. R. Jain, "Ammonium nitrate: a promising rocket propellant oxidizer," Journal of Hazardous Materials, vol. 67, no. 3, pp. 253-281, 1999.

[20] R. S. Chellappa, D. M. Dattelbaum, N. Velisavljevic, and S. Sheffield, "The phase diagram of ammonium nitrate," Journal of Chemical Physics, vol. 137, no. 6, Article ID 064504, 2012.

[21] B. Huang, C. H. Bartholomew, and B. F. Woodfield, "Improved calculations of pore size distribution for relatively large, irregular slit-shaped mesopore structure," Microporous and Mesoporous Materials, vol. 184, pp. 112-121, 2014.

[22] D. B. Bukur, L. Nowicki, R. K. Manne, and X. S. Lang, "Activation studies with a precipitated iron catalyst for fischertropsch synthesis. II. reaction studies," Journal of Catalysis, vol. 155, no. 2, pp. 366-375, 1995.

[23] D. B. Bukur, K. Okabe, M. P. Rosynek et al., "Activation studies with a precipitated iron catalyst for fischer-tropsch synthesis.I. characterization studies," Journal of Catalysis, vol. 155, no. 2, pp. 353-365, 1995.

[24] Y. Jin and A. K. Datye, "Phase transformations in iron Fischer-Tropsch catalysts during temperature-programmed reduction," Journal of Catalysis, vol. 196, no. 1, pp. 8-17, 2000.

[25] H. Jung and W. J. Thomson, "Dynamic X-ray diffraction study of an unsupported iron catalyst in Fischer-Tropsch synthesis," Journal of Catalysis, vol. 134, no. 2, pp. 654-667, 1992.

[26] S. J. Smith, K. Page, H. Kim, B. J. Campbell, J. Boerio-Goates, and B. F. Woodfield, "Novel synthesis and structural analysis of ferrihydrite," Inorganic Chemistry, vol. 51, no. 11, pp. 6421-6424, 2012.

[27] B. Huang, C. H. Bartholomew, and B. F. Woodfield, "Facile structure-controlled synthesis of mesoporous $\gamma$-alumina: Effects of alcohols in precursor formation and calcination," Microporous and Mesoporous Materials, vol. 177, pp. 37-46, 2013.

[28] S. I. Sandler, Chemical and Engineering Thermodynamics, Wiley, New York, NY, USA, 2nd edition edition, 1989. 

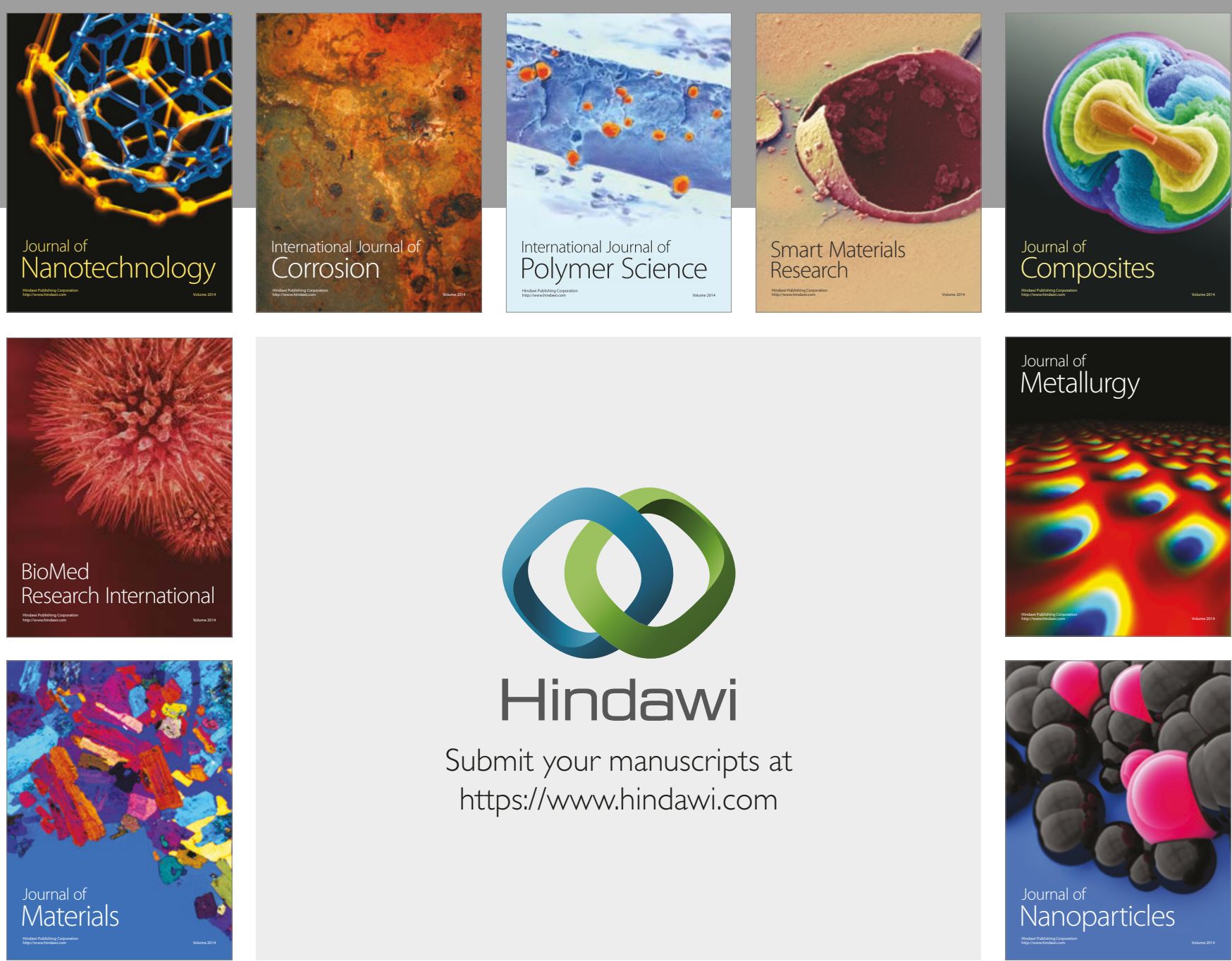

\section{Hindawi}

Submit your manuscripts at

https://www.hindawi.com
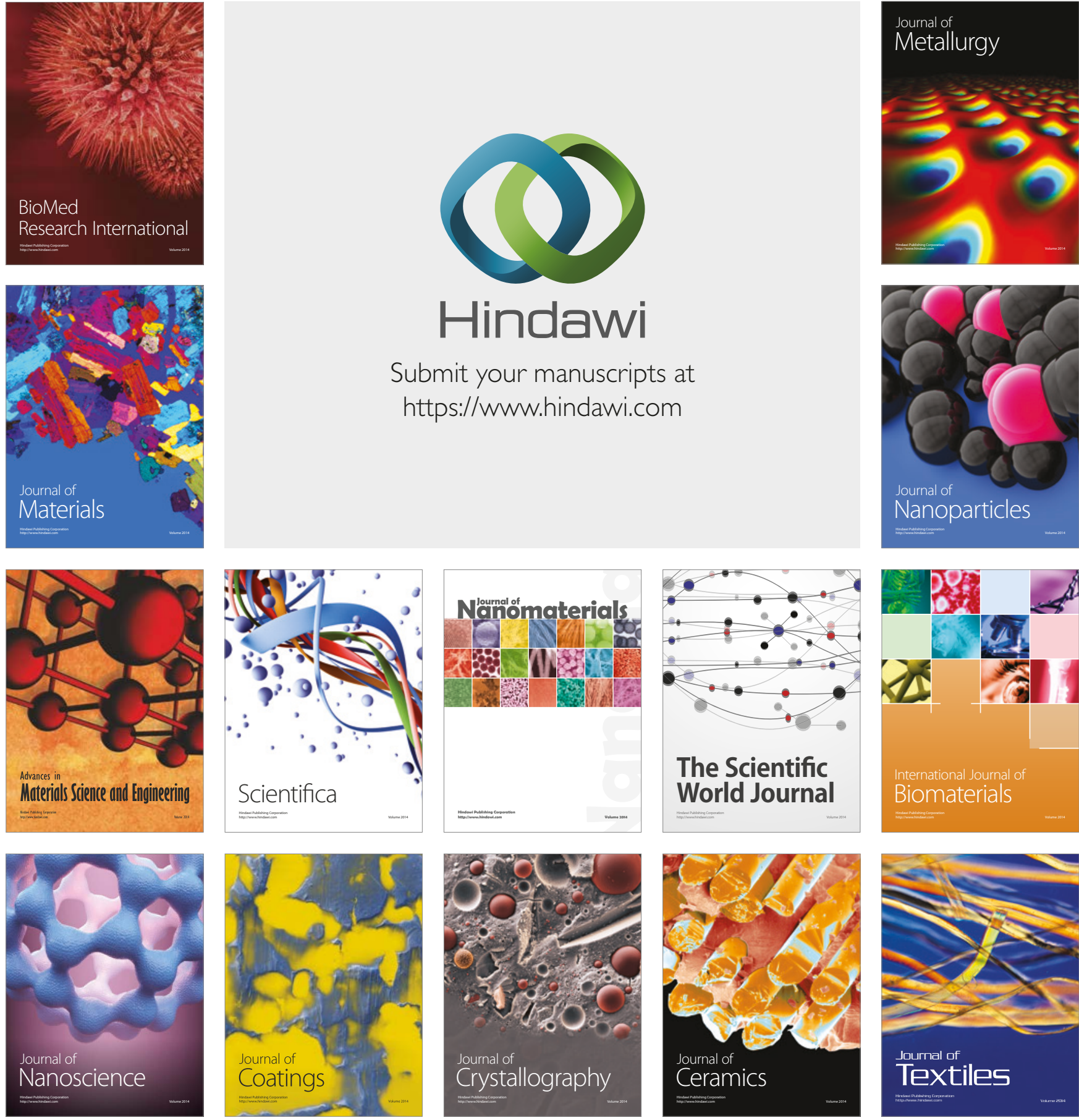

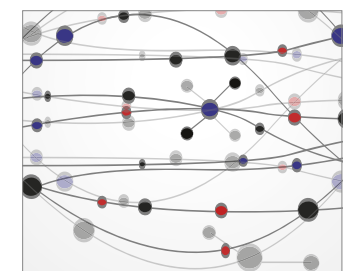

The Scientific World Journal
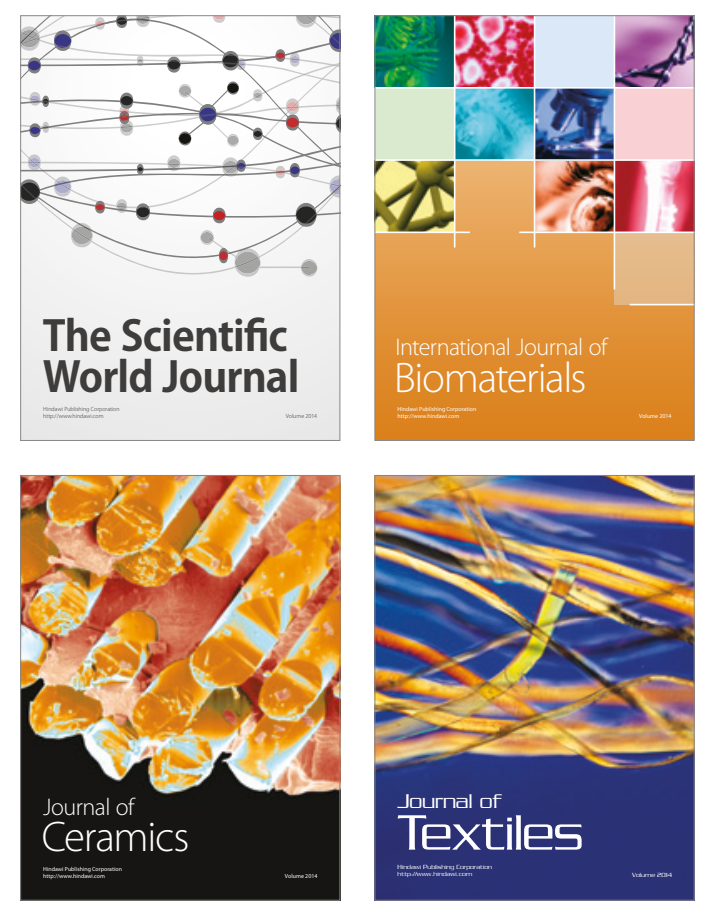